ISSN: 0213-2060

DOI: https://doi.org/10.14201/shhme2021391173196

\title{
INCIDENCIA Y REGULACIÓN DE LAS DINÁMICAS CINEGÉTICAS EN LA SOCIEDAD VISIGODA ${ }^{1}$
}

\author{
Incidence and Regulation of Hunting Dynamics in Visigothic Society
}

\author{
Pablo POVEDA ARIAS \\ DFG Center for Advanced Study "RomanIslam - Center for Comparative Empire and Transcultural Studies». \\ Universität Hamburg Edmund-Siemers-Allee 1. D-20146 HAMBURG. C.e: Pablo.Poveda.Arias@uni-hamburg. \\ de. ORCID: https://orcid.org/0000-0002-2691-7912
}

Recibido: 2020-04-21

Revisado: 2020-09-20

Aceptado: 2020-11-24

RESUMEN: El gran protagonismo dado a los procesos políticos, sociales y religiosos desarrollados en el período visigodo ha provocado que muchas veces los historiadores hayamos dejado de lado otro tipo de problemáticas que, como aquellas de naturaleza económica, ofrecen una información igualmente rica para entender la historia social visigoda. Las dinámicas cinegéticas son una de esas problemáticas que adolecen de una falta de atención por parte de la historiografía. El objetivo del presente estudio es, aparte de llenar el vacío historiográfico sobre esta cuestión, entender la incidencia social y económica de la caza en la sociedad visigoda y su inserción en las dinámicas generales del Occidente post-imperial. Para ello, y en aras de ofrecer una visión lo más global posible, diferenciaremos en nuestro análisis los usos aristocráticos de aquellos más comunes desarrollados por el campesinado.

Palabras clave: Alimentación; Aristocracia; Campesinado; Caza; Historia social; Régimen de propiedad.

ABSTRACT: The major attention given to the political, social and religious processes developed in the Visigothic period has meant that very often historians have left aside other

1 El presente estudio ha sido desarrollado en el marco del Center for Advanced Studies "RomanIslam - Center for Comparative Empire and Transcultural Studies financiado por la Fundación Alemana de Investigación (Deutsche Forschungsgemeinschaft, DFG) y del proyecto de investigación HAR2016-76094 «Formación y dinámica de los espacios comunales ganaderos en el Noroeste de la península ibérica medieval: paisajes e identidades sociales en perspectiva comparada" financiado por el Ministerio de Ciencia e Innovación. Aprovechamos estas líneas para agradecer a Pablo C. Díaz y a los dos evaluadores anónimos sus comentarios y sugerencias, los cuales han contribuido a mejorar el presente estudio. No obstante, la responsabilidad de todo lo aquí defendido es responsabilidad exclusiva del autor. 
types of topics which, like those of an economic nature, offer equally rich information for understanding the social history of Visigothic society. The dynamics of hunting are one of those issues that suffer from a lack of consideration by historiography. The aim of this study is, apart from filling the historiographical gap on this issue, to understand the social and economic impact of hunting in Visigoth society and its insertion in the general trends of the post-imperial West. To this end, and in order to offer the most comprehensive vision possible, we will distinguish in our analysis the aristocratic uses from those more commonly developed by the peasantry.

Keywords: Aristocracy; Diet; Hunting; Land tenure; Peasantry; Social history.

SUMARIO: 0 Introducción. 1 La caza como práctica aristocrática. 2 La caza en los horizontes campesinos. 3 Conclusiones. 4 Referencias bibliográficas.

\section{INTRODUCCIÓN}

Ya sea por su falta de atractivo o porque los focos del debate historiográfico se han centrado en otras problemáticas, lo cierto es que el estudio de las dinámicas económicas de la sociedad visigoda ha suscitado un escaso interés entre los especialistas del periodo y, cuando lo ha generado, este se ha dirigido al análisis de las principales actividades que han articulado todas las sociedades preindustriales, como eran la agricultura y la ganadería $^{2}$. En consecuencia, otras actividades más secundarias, como las vinculadas al aprovechamiento de los recursos salvajes, esto es, la caza o la pesca, se han visto prácticamente marginadas $^{3}$. La caza en particular, a la que dedicamos este trabajo, ha sido analizada de forma muy superficial por los historiadores — procedentes la inmensa mayoría del ámbito jurídico-, y siempre integrando obras de carácter más amplio ${ }^{4}$. Prueba de este

2 Durante la fase post-imperial se desarrollaron de forma equilibrada, incluso sinérgica, ambas actividades. Se ha llegado incluso a hablar de un cruce sistemático, en lugar de una combinación, en lo que se refiere a la explotación de los espacios de cultivo y los incultos dedicados a la ganadería. Devroey, Jean-Pierre. Économie rurale et société dans l'Europe franque (VI'-IX siècles). Tome 1. Fondements matériels échanges et lien social. París: Belin, 2003, p. 28. Dentro de esta línea, Montanari, Massimo. «La foresta come spazio economico e culturale». En Uomo e spazio nell'alto Medioevo. Spoleto: CISAM, 2003, p. 307. Hay autores que, sin embargo, prefieren priorizar una actividad sobre la otra. Entre los que destacan, por ejemplo, la ganadería sobre la agricultura encontramos a King, Paul D. Derecho y sociedad en el reino visigodo. Madrid: Alianza, 1981, p. 227.

3 Ambas actividades habrían tenido una consideración jurídica análoga, precisamente por esta relación que tenían ambas con el mundo salvaje. LRV, Sententia 25. Ed. Gustav Friedrich Haenel, Lex Romana Visigothorum. Leipzig: B. G. Teubner, 1849, p. 390. Otra cuestión también pasada por alto en lo que a los estudios visigotistas se refiere es el uso social de los propios espacios salvajes. Véase Guizard-Duchamp, Fabrice. «Les espaces du sauvage dans le monde franque: réalités et représentations». En Construction de l'espace au Moyen Âge: pratiques et représentations. París: Publications de la Sorbonne, 2007, pp. 117-129.

4 Torres López, Manuel. Lecciones de Historia del Derecho Español, II. Salamanca: Librería General 'La Facultad' de Germán García, 1935-1936, pp. 144-145; Gibert, Rafael. «Introducción». En La acción administrativa en materia de montes y caza. Alcalá de Henares: Escuela Nacional de Administración Pública, 1970, pp. 33-36; King, Derecho, pp. 241-243; Vázquez Cañizares, Julio César. Evolución histórico-legislativa de la caza furtiva. Móstoles: Crealite, 2014, pp. 39-41. 
desinterés es que la mejor aproximación al tema, desarrollada desde el ámbito de la historia del derecho, data de finales del siglo XIX y ni siquiera se encuentra en un estudio monográfico al tema, sino que ocupa un pequeño espacio dentro la magna obra de Eduardo Pérez Pujol dedicada a las instituciones sociales visigodas ${ }^{5}$. Esta situación contrasta con la vigente en otros sectores historiográficos —especialmente del ámbito francés, alemán e italiano- dedicados al estudio de otras realidades geográficas y políticas del Occidente altomedieval, en los que las dinámicas cinegéticas han suscitado en las últimas décadas un cierto interés en su vertiente jurídica, social y alimenticia ${ }^{6}$.

Con el fin de rellenar este vacío historiográfico, a lo largo de las siguientes páginas trataremos de aproximarnos a las prácticas sociales y a los usos jurídicos que condicionaban el ejercicio de la caza en la sociedad visigoda, en lo que constituiría el primer estudio monográfico consagrado a esta cuestión, al menos en lo que al período visigodo se refiere. El objetivo principal es conocer la incidencia social de la actividad cinegética, tanto en contextos aristocráticos como campesinos. El estudio en cuestión no se encuentra exento de dificultades, debido en primer lugar a la parquedad informativa, desde un punto de vista cuantitativo y cualitativo, de las fuentes que, aunque variadas en géneros, tratan este tema de forma meramente anecdótica. Valga como excepción, sin embargo, la documentación de carácter legislativo que, aunque ofrezca pocos exponentes, es la única que presta una atención directa a la caza. A esto se le suman otras leyes que regulan los regímenes de propiedad, las cuales, aunque no tratan directamente esta cuestión, pueden ser de enorme utilidad para rastrear los límites jurídicos en el ejercicio de la caza. Es por ello que, en buena medida, nuestro enfoque ahondará en el conocimiento de la regulación de la actividad cinegética, eso sí, poniéndola en relación con la realidad social concreta. Por otro lado, esta relativa falta de información nos llevará en ocasiones a ofrecer lecturas «en negativo», esto es, interpretando las ausencias de información con respecto a otras realidades históricas contemporáneas que, a diferencia de la visigoda, mostraron aparentemente un mayor interés jurídico y social por las prácticas cinegéticas. Asimismo, en aras de complementar la exigua información documental disponible, nos haremos eco también de algunas de las aportaciones procedentes de la disciplina arqueológica, las

5 Pérez Pujol, Eduardo. Historia de las instituciones sociales de la España goda. Valencia: Establecimiento tipográfico F. Vives Mora, 1896, vol. IV.

6 Lindner, Kurt. Die Jagd im frühen Mittelalter. Berlin: De Gruyter, 1940; Grand, Roger y Delatouche, Raymond. L'agriculture au Moyen Âge. De la fin de l'Empire romain au XVt siècle. París: De Boccard, 1950, pp. 547-618; Verdon, Jean. «Recherches sur la chasse en Occident durant le haut Moyen Âge». Revue Belge de Philologie et d'Histoire, 1978, vol. LVI, n.o 4, pp. 805-829; Le Jan, Régine. «Espaces sauvages et chasses royales dans le nord de la France. VII ${ }^{\text {ème}}-\mathrm{IX}^{\mathrm{ème}}$ siècles». En Le paysage rural: réalités et représentations. Villeneuve d'Ascq: Université de Lille III, 1980, pp. 35-57; "Soustraire, négocier, doner le sauvage au haut Moyen Âge». En Sabaté, Flocel (ed.). Natura i desenvolupament: el medi ambient a l'Edat Mitjana. Lleida: Pagès, 2007, pp. 57-72; Pacaut, Marcel. «Esquisse de l'évolution du droit de chasse au haut Moyen Âge». En La chasse au Moyen Âge. París: Les Belles Lettres, 1980, pp. 59-68; Jarnut, Jörg. "Die frühmittelalterliche Jagd unter rechts- und sozialgeschichtlichen Aspekten». En L'uomo di fronte al mondo animale nell'alto Medioevo. Spoleto: CISAM, 1985, vol. II, pp. 765-808; Rösener, Werner (ed.). Jagd und höfische Kultur im Mittelalter. Göttingen: Vandenhoeck \& Ruprecht, 2000. Desde el ámbito de la historia de la alimentación, Montanari, Massimo. L'alimentazione contadina nell'alto Medioevo. Napoli: Liguori, 1979 como máximo exponente, aunque sin embargo ignora en su análisis la realidad visigoda. 
cuales, a través de análisis zooarqueológicos o isotópicos, resultan enormemente elocuentes a la hora de conocer la incidencia alimenticia de los productos derivados de la caza en el seno de las comunidades, en especial en aquellas de eminente naturaleza campesina.

\section{LA CAZA COMO PRÁCTICA ARISTOCRÁTICA}

Las investigaciones en torno a las dinámicas cinegéticas del Occidente post-imperial se han centrado especialmente en el estudio de su vertiente aristocrática, una atención que por otro lado cobra sentido dado el mayor volumen de información disponible en comparación a aquella referida a contextos campesinos. Una de las primeras conclusiones que extraemos de tales fuentes es la importancia de la caza como actividad rutinaria entre los sectores poderosos de la sociedad ${ }^{7}$. En los espacios políticos galos e itálicos, por ejemplo, esta se convirtió en una actividad de recreo y formativa que denotaba distinción aristocrática y militar en aquellos que la practicaban ${ }^{8}$, predominando este factor ideológico sobre el productivo y alimenticio". No debemos, sin embargo, asociar necesariamente este factor militar con una germanización del comportamiento de las élites y, por extensión, de los monarcas. De hecho, la caza se trataba de una actividad recreativa propia de la cultura aristocrática tardorromana ${ }^{10}$, la cual a su vez bebía de las tradiciones helenísticas ${ }^{11}$. Con todo, se advierte una importancia social creciente de esta actividad en los contextos privilegiados post-imperiales, que, debido a su práctica colectiva, se convirtió en una de las plataformas preferentes de socialización entre los potentes ${ }^{12}$. Por otro lado, ya fuera como causa o consecuencia de esto último, la caza se convirtió en un escenario de competición de las élites, por ejemplo, mostrando unas mejores habilidades físicas y militares o unos mayores recursos materiales ${ }^{13}$. Dentro de estos últimos, aparte

7 Verdon, «Recherches», p. 805.

8 Ibidem, pp. 826-828; Le Jan, «Espaces sauvages», pp. 35-57; «Soustraire, négocier», pp. 62-64; Montanari, L'alimentazione, pp. 257, 261-268; «La foresta», p. 316; Wickham, Chris. «European Forests in the Early Middle Ages: Landscape and Land Clearance». En L'ambiente vegetale nell'alto Medioevo. Spoleto: CISAM, 1990, p. 487; Devroey, Économie, pp. 91-94. En contra de esta idea, Guerreau, Alain. «La caza». En Le Goff, Jacques y Schmitt, Jean-Claude (eds.). Diccionario razonado del Occidente medieval. Madrid: Akal, 2003, p. 137. Es en este sentido en el que entendemos la prohibición que se impuso a los clérigos de practicar la caza. Véase a este respecto, Verdon, «Recherches», p. 810.

9 Montanari, «La foresta», p. 315.

10 Aymard, Jacques. «Sidoine Apollinaire et la chasse». En Renard, Marcel y Schilling, Robert (eds.). Hommages à Jean Bayet. Bruselas: Latomus, 1964, pp. 47-53; Raga, Emmanuelle. «Réflexions sur le rapport ville/campagne dans l'Antiquité tardive au travers de quelques discours sur la chasse». Revue Belge de Philologie et d'Histoire, 2011, vol. LXXXIX, n. ${ }^{\circ}$ 2, pp. 659-667.

11 García Garrido, Manuel J. "Derecho de caza y 'ius prohibendi' en Roma». Anuario de Historia del Derecho Español, 1956, vol. XXVI, pp. 270-271. Niega, sin embargo, la naturaleza lúdica de la caza en la sociedad romana: De los Mozos, José Luis. «Precedentes históricos y aspectos civiles del derecho de caza». Revista de Derecho Privado, 1972, vol. LVI, n.o 4, p. 287.

12 Montanari, L'alimentazione, p. 258.

13 Giese, Martina. «Kompetitive Aspekte höfischer Jagdaktivitäten im Frühmittelalter». En Becher, Matthias y Plassmann, Alheydis (eds.). Streit am Hof im frühen Mittelalter. Göttingen: Vandenhoeck \& 
del armamento, entre el cual el arco y el venablo destacarían ${ }^{14}$, también la exhibición de animales, a los que se llegaba a ataviar de ropas para la ocasión, habría desempeñado un papel similar en el juego competitivo ${ }^{15}$. Por ejemplo, Sidonio Apolinar, cuando alaba las habilidades cinegéticas de la figura de Namacio, destaca la naturaleza excepcional de sus perros de caza, dejando así muestra del impacto social que tenía la exhibición de más y mejores recursos ${ }^{16}$.

La importancia de la caza como práctica social aristocrática habría tenido también su incidencia en el comportamiento de los monarcas. Así lo revela, por ejemplo, en el caso franco, la erección por parte de los reyes merovingios y carolingios de palatia rurales en entornos boscosos a modo de residencias de caza ${ }^{17}$. Más llamativa resulta la restricción de uso que algunos reinos hicieron de los espacios cinegéticos por excelencia, como son los bosques, llegando a hacer una distinción explícita en la legislación entre los bosques reales y los de uso común. ${ }^{18}$ Antes incluso de la promulgación de una normativa específica, los reyes ya empezaron a reservarse de facto el derecho exclusivo de explotación cinegética de tales espacios, llegando a castigar con la muerte a aquel que se atreviese a cazar en una regalis silua sin su permiso, tal y como hizo el rey merovingio Gontran (561-692) con uno de sus servidores palatinos ${ }^{19}$. Para velar por estos derechos de uso exclusivos, los monarcas merovingios llegaron a nombrar cargos específicos a modo de guardabosques $(\text { custos siluae })^{20}$; un fenómeno que también se reprodujo en el reino longobardo ${ }^{21}$. Tales

Ruprecht, 2011, pp. 263-284, esp. 276-279. Un comportamiento similar se ha percibido también en los entornos regios. Le Jan, "Soustraire, négocier», p. 63.

14 Sid. Apoll., Ep. I, 2. Ed. André Loyé. Sidoine Apollinaire, Tome II, Lettres (Livres I-V). París: Les Belles Lettres, 1970, p. 4-8; VIII, 6, 11. Ed. André Loyé. Sidoine Apollinaire, Tome III, Lettres (Livres VI-IX). París: Les Belles Lettres, 1970, p. 95; Isid. Hisp., Etym. V, 283. Ed. José Oroz Reta y Manuel-A. Marcos Casquero. Etimologías. Madrid: BAC, 2009, p. 842.

15 Sid. Apoll., Ep. III, 3, 2; IV, 9, 2.

16 Sid. Apoll., Ep. VIII, 6, 11.

17 Le Jan, "Espaces sauvages», pp. 38-40; Barbier, Josiane. "Le système palatial franc: genèse et fonctionnement dans le nord-ouest du regnum". Bibliothèque de l'École des Chartes, 1990, vol. CXLVIII, n. ${ }^{\circ}$, pp. 245-299; Rollason, David. "Forests, Parks, Palaces, and the Power of Place in Early Medieval Kingship». Early Medieval Europe, 2012, vol. 20, n. ${ }^{\circ} 4$, pp. 431-432 y 435.

18 Lex Ribuaria. 79. Ed. Franz Beyerle y Rudolf Buchner. Lex Ribuaria. MGH, LL nat. Germ., T. III, P. II, Hannover: Impensis Bibliopolii Hahniani, 1954, pp. 129-130; Edictus Rothari, 319-320. Ed. Georg Heinrich. Pertzt. Leges Langobardorum. MGH, Legum, T. IV, Hannover: Impensis Bibliopoli Hahniani, 1868, pp. 73-74. Para un recorrido legislativo sobre esta cuestión, Le Jan, «Espaces sauvages», p. 42.

${ }_{19}$ Greg. Tur., DLH, X, 10. Ed. Bruno Krusch y Wilhelm Levison. Gregorii episcopi Turonensis Historiarum Libri X. MGH, SRM Tom. I P. I. Hannover: Impensis Bibliopolii Hahniani, 1951, p. 494.

20 Greg. Tur., DLH, X, 10. Verdon, «Recherches», pp. 807-809, 813. La bibliografía que ha reparado sobre este fenómeno es muy numerosa. A modo de selección: Higounet, Charles. «Les forêts de l'Europe occidentale du $\mathrm{v}^{\mathrm{e}}$ au XI ${ }^{\mathrm{e}}$ siècle». En Agricoltura e mondo rurale in occidente. Spoleto: CISAM, 1966, p. 376; Le Jan, «Espaces sauvages», pp. 42-45; «Soustraire, négocier», pp. 59-65; Wickham, «European Forests», pp. 485-486; Devroey, Économie, pp. 34-36; Guizard-Duchamp, «Les espaces», p. 125. En un plano más general, Montanari, «La foresta», pp. 311-313.

${ }_{21}$ Cigolini, Francesco. Il diritto di caccia nella legislazione statale e regionale. Milano: A. Giuffrè, 1959, p. 6; Wickham, «European Forests», p. 486. 
espacios de uso restringido según el criterio regio recibirán desde el siglo viı el nombre de foresta ${ }^{22}$.

En el reino visigodo, sin embargo, las evidencias que documentan la caza como práctica aristocrática son excepcionales. Además, de los pocos exponentes disponibles, la mayor parte se refiere a la fase tolosana del reino y, por tanto, la situación descrita se circunscribe eminentemente al ámbito galo ${ }^{23}$. Por ejemplo, Sidonio Apolinar destaca la caza como una de las actividades cotidianas a las que se dedicaba la aristocracia gala, especialmente durante la juventud, llegándose incluso a destacar el buen ejercicio de esta como una virtud que denotaba distinción ${ }^{24}$. Se advierte, por tanto, un cierto gusto en el reino visigodo, al menos en su fase tolosana, por la práctica cinegética ${ }^{25}$. Esta inclinación por la caza se observa también entre los reyes visigodos, tal y como recoge el mismo Sidonio cuando se dispone a retratar la figura de Teodorico II (453-466). A partir de la lectura de una de sus cartas se descubre que la caza promovida desde el ámbito cortesano tenía un cierto carácter oficial al ser anunciada con cierta antelación. En tales episodios, destacaría la propia implicación del rey, de quien se subrayan sus habilidades cinegéticas, como por ejemplo su puntería con el $\operatorname{arco}^{26}$. Como ocurría en el caso de la aristocracia, tales virtudes habrían tenido también en este caso una vertiente militar, poniendo así de manifiesto las habilidades guerreras del monarca. Esta relación de la caza con la actividad militar se pone de relieve en otro de los pocos testimonios disponibles, presumiblemente también referido a la etapa tolosana, recogido en este caso en el primer libro de la vida hagiográfica dedicada a Cesáreo de Arlés. En él se relata cómo el obispo de Arlés logró la intercesión divina para lograr que los jabalíes dejasen de rondar el territorio de la ciudad, puesto que estos animales atraían la atención de los mandos militares visigodos y las tropas a su cargo, que organizaban partidas de caza, pero con ellas provocaban al mismo

22 Así ocurrió, por ejemplo, en las Ardenas. Diplom. Merov. 108, 27. Ed. Theo Kölzer. Die Urkunden der Merowinger. MGH, Diplomata regum Francorum e stirpe Merovingica. Hannover: Impensis Bibliopolii Hahniani, 2001, vol. 1, p. 279. Sobre las foresta, véase Lorenz, Sönke. "Der Königsforst («forestis») in den Quellen der Merowinger- und Karolingerzeit: Prolegomena zu einer Geschichte mittelalterlicher Nutzwälder». En Bauer, Dieter R., Hiestand, Rudolf, Kasten, Brigitte y Lorenz, Sönke (eds.). Mönchtum - Kirche - Herrschaft: 750-1000. Sigmaringen: Jan thorbecke Verlag, 1998, pp. 261-285; Le Jan, «Soustraire, négocier", pp. 64-67. Tales restricciones prefiguran así el establecimiento posterior del dominio señorial que imperará sobre tales espacios en el período feudal. Tal y como afirma Wickham, «European Forests», p. 488, "the history of hunting closely mirrors that of political power and socio-political change, and the history of forest rights, similarly, that of the development of other legal rights and powers over property». Poniendo de relieve la importancia de la práctica social cinegética como forma de apropiación territorial, Morsel, Joseph. "Construire l'espace sans la notion d'espace: Le cas du Salzforst (Franconie) au Xvi ${ }^{e}$ siècle». En Construction de l'espace au Moyen Âge: pratiques et représentations. París: Publications de la Sorbonne, 2006, pp. 312-314. Sobre los derechos de caza en época altomedieval y su vinculación a la propiedad, véase Pacaut, "Esquisse», pp. 59-68.

23 Sobre la importancia de los rituales cinegéticos en el reino visigodo de Tolosa, Valverde Castro, M. ${ }^{a}$ Rosario. Ideología, simbolismo y ejercicio del poder real en la monarquía visigoda: un proceso de cambio. Salamanca: Universidad de Salamanca, 2000, pp. 104-105.

24 Sid. Apoll., Ep. III, 3, 2; IV , 4, 1; IV, 9, 3; V, 11, 2; V, 17, 1; VIII, 6, 11. Aymard, «Sidoine Apollinaire», pp. 50-53.

25 Lindner, Kurt. Die Jagd, pp. 38-39.

26 Sid. Apoll., Ep. I, 2, 5. Véase Aymard, «Sidoine Apollinaire», p. 49. 
tiempo graves daños a las tierras del campesinado del entorno ${ }^{27}$. A la vista de dicho episodio, da la impresión de que la caza entraba dentro de las rutinas de entrenamiento militar del ejército visigodo.

Es dentro de una obra donde el elemento militar adquiere pleno protagonismo donde se enmarca el otro testimonio, el único referido al reino visigodo hispano, que deja constancia, al menos de forma indirecta, del ejercicio de la caza como práctica regia ${ }^{28}$. Nos referimos a la supuesta carta que, hipotéticamente, el rebelde Paulo envió a Wamba (672-680) en su desafío contra el rey visigodo y que precede a la Historia Wamba en la que se relata con detalle el conflicto militar entre ambos. En la epístola en cuestión se dice, con un cierto tono burlón, que el monarca visigodo invertía parte de su tiempo en los montes y en los bosques, entre animales salvajes ${ }^{29}$. De esta manera, el texto dibuja el típico escenario cinegético ${ }^{30}$, asociando estos espacios con la presencia de los animales más cazados en la caza aristocrática como eran las cabras montesas, los ciervos y los jabalíes $^{31}$. Más allá del posible carácter ficticio de la carta, la cual pudo ser en realidad redactada por Julián de Toledo, esta se basa en hechos históricos veraces producidos poco antes de la redacción de este texto epistolar ${ }^{32}$. Entre ellos, la dedicación regia de la caza es uno de esos elementos cuya historicidad no debe cuestionarse. De hecho, se habría tratado de un detalle que habría servido a su autor para dotar de una mayor credibilidad a la carta

27 Vita Caesarii I, 48. Ed. Bruno Krusch. Passiones vitaeque sanctorum aeui Merouingici et antiquiorum aliquot. MGH, SRM, T. III. Hannover: Impensis Bibliopolii Hahniani, 1896, pp. 475-476.

28 Ello contrasta con los numerosos episodios disponibles para el caso merovingio. Por ejemplo: Greg. Tur., DLH IV, 21; V, 39; VI, 46; VIII, 6; VIII, 10; X, 10.

${ }_{29}$ Epistula ad Wambanem principem, 2-6. Ed. Wilhelm Levison. Sancti Iuliani Toletanae sedis episcopi opera, Pars I. CC, Series Latina, CXV. Turnhout: Brepols, 1976, p. 217.

30 P. C. Díaz, por su parte, en el comentario histórico que hace de esta carta, plantea que el fragmento en cuestión tenía un doble sentido, aludiendo en realidad a las gentes de las montańas con las cuales combatió Wamba. Martín-Iglesias, José Carlos, Díaz, Pablo C. y Vallejo Girvés, Margarita. La Hispania tardoantigua y visigoda en las fuentes epistolares. Antología y comentario. Madrid: CSIC, 2020, pp. 757-759. Mi agradecimiento a los autores por haberme permitido consultar el volumen antes de su publicación.

31 Sidonio Apolinar destaca el jabalí, el ciervo y la cabra montesa como los animales habituales de la caza aristocrática. Sid. Apoll., Ep. VIII, 6, 11. De todos estos, posiblemente el ciervo constituía la pieza más cazada y ambicionada. Montanari, Massimo. "Gli animali e l'alimentazione umana", en L'uomo di fronte al mondo al mondo animale nell'alto Medioevo. Spoleto: CISAM, 1984, pp. 632-633. Así ocurría, por ejemplo, en el reino merovingio. Greg. Tur., Lib. in Glor. Confess. 86. Ed. Bruno Krusch. Gregorii episcopi Turonensis miracula et opera minora. MGH, SRM Tom. I P. II. Hannover: Impensis Bibliopolii Hahniani, 1885, p. 354. A la misma idea apunta el mayor número de restos de cérvido encontrados en el registro zooarqueológico disponible, con independencia del momento histórico. Véase Audoin-Rouzeau, Frédérique. "L'alimentation carnée dans l'Occident antique, médiéval et moderne. Identités culturelles, sociales et regionales à travers le temps». En Laurioux, Bruno (ed.). Histoire et identités alimentaires en Europe. París: Hachette, 2002, pp. 8183. El atractivo por el jabalí, en cambio, decaerá a partir de estos momentos, al menos en comparación con períodos antiguos. Ibidem, p. 84. La caza del oso, animal que también se menciona en la supuesta carta de Paulo, habría tenido un carácter más excepcional.

32 Sobre la problemática que gira en torno a esta carta, tanto en lo relativo a su autoría como a su historicidad, véase Deswarte, Thomas. «Une satire politique. La lettre de Paul à Wamba (672)». En Deswarte, Thomas, Herbers, Klaus y Sirantoine, Hélene (eds.). Epistola 1. Écriture et genre épistolaires IVe-XI siècle. Madrid: Casa de Velázquez, 2018, pp. 129-137. 
en cuestión, de ahí su validez como testimonio ${ }^{33}$. La naturaleza tardía del texto apunta, por tanto, a que la caza formó parte durante todo el período visigodo del catálogo de actividades practicadas por los monarcas. Por su parte, el tono burlón aplicado por la mencionada carta al referirse a la ocupación cinegética de Wamba apunta, no tanto a una desconsideración hacia esta como práctica, sino a su relegación en el orden de prioridades cuando aparecía una amenaza militar mayor o, como se dice en el texto, un enemigo más digno contra el cual llevar a la práctica, en un escenario militar real, las habilidades manifestadas hasta entonces en un plano recreativo ${ }^{34}$. En contextos más rutinarios la caza practicada por los monarcas habría desempeñado un papel similar al percibido en los reinos francos, donde los reyes exhibían su superioridad frente al resto a través de la práctica cinegética ${ }^{35}$. Con ello lograría incluso generar la admiración de su gente e incluso atraer $\operatorname{adeptos}^{36}$. Prueba de ello la tenemos en la ya citada carta de Sidonio, donde el autor, al admirar las habilidades cinegéticas de Teodorico II, destaca su puntería con el $\operatorname{arco}^{37}$. Tales beneficios habrían lanzado a los reyes a implicarse activamente en la caza ${ }^{38}$, aunque ello supusiese poner en riesgo sus propias vidas. De hecho, sabemos que uno de los reyes merovingios, Teodeberto I, murió como consecuencia de las heridas provocadas en uno de estos episodios ${ }^{39}$. Por otro lado, dentro de los beneficios que podía reportar la caza al poder regio, esta ofrecía también la oportunidad de reforzar los vínculos entre el monarca y la aristocracia que participaba en estas partidas ${ }^{40}$.

Otro testimonio aislado, en este caso recogido en las Etimologías de Isidoro de Sevilla, apunta a una cierta especialización y distribución de funciones en la caza aristocrática, entre aquellos que se dedicaban a las tareas de rastreo y aquellos que se enfrentaban directamente a los animales ${ }^{41}$. Sin embargo, posiblemente esta especialización nunca llegó a

33 Haciéndonos eco de las palabras de Chris Wickham, ello entraría dentro del "campo retórico de aceptación de lo que resultaba verosímil decirle a alguien en un momento determinado». Wickham, Chris. Una historia nueva de la Alta Edad Media, 400-800. Barcelona: Crítica, 2009, p. 46. Este mismo principio puede aplicarse a la noticia anteriormente referida de la Vita Caesarii. Véase supra.

34 Epistula ad Wambanem principem, 6-12.

35 Le Jan, «Espaces sauvages», pp. 37-38. Véase también Rollason, «The Power of Place», pp. 440-442.

36 Esta idea es aplicable al conjunto de monarquías a lo largo de la historia. Betzig, Laura. «Hunting Kings». Cross-Cultural Research, (2008) vol. 42, n. ${ }^{\text {3 }}$, pp. 270-289, esp. 283-285.

37 Sid. Apoll., Ep. I, 2, 5. Véase Aymard, «Sidoine Apollinaire», p. 49. Sobre la figura del rey cazador entre la Antigüedad y la Edad Media, véase Rösener, Werner. «Der König als Jäger. Antike Einflüsse auf di herrschaftliche Jagd im Mittelalter». En Martini, Wolfram (ed.). Die Jagd der Eliten in den Erinnerungskulturen von der Antike bis in die Frühe Neuzeit. Göttingen: Vandenhoeck \& Ruprecht, 2000, pp. 15-37.

38 Por unas razones similares los monarcas también se vieron obligados en cierta medida a exponer sus vidas en el campo de batalla cuando lideraban campañas militares. Véase Halsall, Guy. "Predatory Warfare - the Moral and the Physical». En Keller, Rodolphe y Sarti, Laury (eds.). Pillages, tributs, captifs. Prédation et sociétés de l'Antiquité tardive au haut Moyen Âge. París: Éditions de la Sorbonne, 2018, pp. 53-68, esp. 61.

39 Agath. Hist. I, 4. Ed. Rudolf Keydell. Agathiae Myrinaei Historiarum libri quinque. Berlin: De Gruyter, 1967, pp. 21-23.

40 Rollason, «The Power of Place», p. 439.

41 Isid. Hisp., Etym. V, 283. Este tipo de especialización, creemos, habría sido más propio de la caza de recreo desarrollada por las élites, dado el componente colectivo que se advierte, y no tanto de aquella propia de ámbitos campesinos, llevada a cabo con eminentes intereses alimenticios y económicos y la cual, como veremos más adelante, habría sido practicada de forma más individual. 
alcanzar aquella percibida en otros ámbitos geográficos, como el galo o el germano, donde se adiestraron razas especiales de perros para los ejercicios cinegéticos, con funciones específicas para cada una, lo que hacía de ellos bienes muy valiosos para su posesor ${ }^{42}$. En la sociedad visigoda también se recurrió al perro como animal de caza, pero no tenemos evidencias de una selección tan especializada de razas como en el caso franco ${ }^{43}$.

Dentro de esta especialización debemos incluir también la cetrería. Las fuentes apuntan a un uso cinegético de halcones ${ }^{44}$, mientras que la zooarqueología ha identificado también la crianza de azores en algunos espacios ${ }^{45}$. Ya en tiempos del concilio de Agde se menciona la cetrería como una práctica compartida por godos y romanos ${ }^{46}$. No es descartable, por tanto, que hubiese sido introducida por los pueblos germánicos al asentarse en el Imperio ${ }^{47}$, pero es difícil atribuir tal fenómeno a los visigodos ${ }^{48}$. Con todo, lo cierto es que a partir del siglo v esta técnica cinegética adquirió una importancia creciente, convirtiéndose incluso en un signo de distinción ${ }^{49}$. Sin embargo, con los datos disponibles, por nuestra parte no podemos asociar su presencia a contextos de prestigio, pero al menos estos sí permiten avalar esa especialización en la actividad cinegética. Aun así, debemos asumir que aquellos que gozaban de una mejor posición económica y social estaban en mejores condiciones para hacer frente a los costes de obtención y entrenamiento de este tipo de animales ${ }^{50}$.

Lamentablemente, no disponemos de más información documental que nos permita conocer con mayor profundidad la incidencia social que tenía la caza como práctica aristocrática en la sociedad visigoda. De esta forma, y a diferencia de lo que ocurría en los reinos vecinos, no contamos con noticia alguna que apunte a una restricción en el

42 Véase Grand y Delatouche, L'agriculture, pp. 607-610; Salisbury, Joyce E. The Beast Within. Animals in the Middle Ages. New York: Routledge, 1994, pp. 35-47; Bord, Lucien-Jean y Mugg, Jean-Pierre. La chasse au Moyen Âge. Occident latin, VI -XV siècle. Chartres: Éditions du Gerfaut, 2008, p. 226.

43 Isid. Hisp., Etym. XII, 2, 26.

44 Isid. Hisp., Etym. XII, 7, 1.

45 Concretamente, se han encontrado restos de esqueleto de azores en contextos domésticos de Buzanca y Begastri, además en hábitats impropios paras estos animales. Véase Llorente, Laura, Morales-Muñiz, Arturo, Cirujano, Fernando, Daza, Arantxa y Liesau, Corina. «Earliest archaeozoological evidence of falconry in the Iberian Peninsula». En BoneCommons, 2010, Item \#1324. URL:http://alexandriaarchive.org/ bonecommons/exhibits/show/icaz2010París/session5_2_\%26_6_3/item/1324 [Consultado el 17/04/2020]; Grau-Sologestoa, Idoia. «Socioeconomic Status and Religious Identity in Medieval Iberia: The Zooarchaeological Evidence». Environmental Archaeology, 2017, vol. 22, n. ${ }^{\circ}$ 2, p. 193. Los azores habrían sido también empleados en el mundo franco. Greg. Tur., $D L H \mathrm{~V}, 14$. Ofreciendo una tipología de las aves empleadas en la caza durante la Alta Edad Media, Grand y Delatouche, L'agriculture, p. 611.

46 Conc. Agath. (a. 506), c. 55. Ed. Charles Munier. Concilia Galliae. A $314-$ A. 506. Turnhout: Brepols, 1963, p. 226. Así lo pone de manifiesto también Pérez Pujol, Historia, p. 340.

47 Guerreau, «La caza», p. 139.

48 Véase también Wolfram, Herwig. History of the Goths. Berkeley: California University Press, 1988, p. 115 .

49 Sid. Apoll., Ep. III, 3, 2; IV , 9, 2. El propio emperador Avito, procedente de la Galia, habría dominado esta técnica de caza. Sid. Apoll., Carm. VII, 202-206. Ed. André Loyen. Sidoine Apollinaire, Tome I, Poèmes. París: Les Belles Lettres, 1960, p. 62. Véase Aymard, «Sidoine Apollinaire», p. 49; Verdon, «Recherches», pp. 819-821. Es posible incluso vincular su introducción con la intensificación de la caza de aves que la zooarqueología advierte a partir del período altomedieval. Audoin-Rouzeau, «L'alimentation carnée», p. 84

50 Grau-Sologestoa, «Socioeconomic Status», p. 195. 
ejercicio de la caza en las propiedades regias, a pesar de contar en el reino visigodo con la recopilación legal más importante y detallada del Occidente post-imperial. Este silencio de las fuentes, en especial en las de carácter legislativo, apunta por tanto a la inexistencia de reservas de caza de uso exclusivo para los monarcas o para un grupo social concreto, dando así continuidad a las costumbres jurídicas romanas en este asunto que, como retomaremos más adelante, otorgaban una libertad de caza con independencia del estatus jurídico y social de cada persona ${ }^{51}$. ¿Qué razón podía estar detrás de este particularismo visigodo? En aras de responder a esta pregunta, es posible que uno de los factores que motivó la creación de cotos de caza de derecho exclusivo en otros espacios hubiese obedecido a una presión y explotación cinegéticas excesivas sobre los bosques y montes que hubiesen provocado una depauperización de los recursos cinegéticos en determinadas regiones $^{52}$. A fin de cuentas, los palatia rurales merovingios se encuentran concentrados en la misma franja geográfica del norte del regnum Francorum ${ }^{53}$, que coincide con el centro político merovingio y con la zona más boscosa de la Galia ${ }^{54}$. La radicación aquí de las cortes merovingias habría atraído a la aristocracia franca a esta región ${ }^{55}$, provocando a su vez una concurrencia en la explotación cinegética de estos espacios ${ }^{56}$.

A la vista de la realidad franca, y frente al silencio informativo que impera en la aprehensión de las dinámicas visigodas, es posible que en el reino visigodo no se hubiese dado nunca una presión relevante sobre los espacios cinegéticos, haciendo así innecesarias medidas que restringiesen el ejercicio de la caza. Ello se pudo deber a que, aun practicándose, su incidencia en los estratos más altos de la sociedad debió de ser bastante relativa, a lo que se puede sumar una mayor dispersión geográfica en su ejercicio ${ }^{57}$. En aras de dar fuerza a nuestros argumentos, la zooarqueología puede convertirse en un

51 García Garrido, «Derecho de caza», p. 336.

52 Subrayando la importancia de estas restricciones de uso de una determinada propiedad como factor de preservación ecológica, Morales Muñiz, Arturo y Morales Muñiz, Dolores Carmen. «¿De quién es este ciervo?: algunas consideraciones en torno a la fauna cinegética de la Espańa medieval». En Clemente Ramos, Julián (coord.). El medio natural en la España medieval. Cáceres: Universidad de Extremadura, 2001, p. 401. A diferencia de lo que ocurrió en períodos más tardíos, consideramos que en ningún momento esta "política ecológica» fue concebida para limitar de forma expresa la explotación campesina de estos espacios. Montanari, L'alimentazione, pp. 254-255. En su lugar, nos inclinamos más a pensar que, al menos en estos contextos de la temprana Alta Edad Media, tales limitaciones se establecieron de cara a la aristocracia.

53 Barbier, Josiane. «Les lieux du pouvoir en Gaule franque». En Ehlers, Caspar (ed.). Places of Power - Orte der Herrschaft - Lieux du Pouvoir. Göttingen: Vandenhoeck \& Ruprecht, 2007, pp. 227-246.

54 Cardot, Fabienne. L'espace et le pouvoir. Étude sur l'Austrasie mérovingienne. París: Publications de la Sorbonne, 1987 , p. 113.

55 Sobre la radicación aristocrática en el norte de la Galia y su dependencia del poder regio, Wickham, Una historia, pp. 271-279.

56 Gracias a recientes estudios, se ha constatado la presencia de importantes familias aristocráticas en estas regiones boscosas, como es el caso de las Ardenas. Devroey, Jean-Pierre y Schroeder, Nicolas. «Beyond Royal Estates and Monasteries: Landownership in the Early Medieval Ardennes». Early Medieval Europe, 2012, vol. 20, n. ${ }^{\circ}$, pp. 39-69, esp. 51.

57 Es posible que la uilla de Gérticos situada en el territorium Salmaticensis, donde murió el rey Recesvinto, hubiese desempeńado estas funciones cinegéticas en un espacio, además, alejado de la corte toledana. Iul. Tolet., Hist. Wamb. 3. Ed. Wilhelm Levison. Sancti Iuliani Toletanae sedis episcopi opera, Pars I. CC, Series Latina, CXV. Turnhout: Brepols, 1976, pp. 219-220. 
instrumento de utilidad a la hora de aproximarnos un poco más a la incidencia de la caza en la sociedad visigoda, y en concreto a su dieta, aunque si bien es cierto que, tal y como reconocen los especialistas, se trata de una materia aún pendiente, al menos en lo que a estas cronologías se refiere ${ }^{58}$. Los resultados ofrecidos por esta disciplina, pero también por los análisis de isótopos realizados sobre algunos restos humanos hallados en contextos de necrópolis, apuntan a un consumo muy excepcional de carne procedente de la caza, el cual se identifica en lugares muy específicos del panorama ibérico ${ }^{59}$. Partiendo de esta base, se han encontrado restos de ciervo y conejo tanto en contextos campesinos como aristocráticos ${ }^{60}$, aunque es cierto que en estos últimos la variedad de animales salvajes hallados es mayor, concretamente aquellos de más difícil captura como el cervatillo o el oso, que necesitan un mayor grado de especialización militar ${ }^{61}$. Aun así, en un plano general, ni siquiera en estos contextos privilegiados, donde sí se han encontrado otros marcadores que apuntan a una presencia de grupos sociales privilegiados o emergentes ${ }^{62}$, destaca el

58 Una introducción a las problemáticas que plantea esta disciplina en los contextos tratados y posteriores, Grau-Sologestoa, Idoia y García-García, Marcos. "Zooarqueología y Edad Media en la península ibérica». En Quirós Castillo, Juan Antonio (ed.). Treinta años de Arqueología Medieval en España. Oxford: Archaeopress, 2018, pp. 341-364.

59 García-Collado, Maite Iris. «Food Consumption Patterns and Social Inequality in an Early Medieval Rural Community int he Centre of the Iberian Peninsula». En Quirós Castillo, Juan Antonio (ed.). Social Complexity in Early Medieval Rural Communities: the North-Western Iberia Archaeological Record. Oxford: Archaeopress, 2016, p. 63; Grau-Sologestoa, «Socioeconomic Status», p. 191. Situaciones similares se han identificado en otros contextos. Baker, Polydora. «Le rôle de la chasse comme moyen de subsistance durant le haut Moyen Âge dans le nord de l'Italie: une comparaison des sources zooarchéologiques et historiques». En Desse, Jean y Audoin-Rouzeau, Frederique (eds.). Exploitation des animaux sauvages à travers le temps. Juan-les-Pins: Éditions APDCA, 1983, pp. 505-516; Pearson, Kathy. «Salic Law and Barbarian Diet». En Mathisen, Ralph W. (ed.). Law, Society, and Authority in Late Antiquity. New York-Oxford: Oxford University Press, 2001, pp. 280-281, quien habla de una infra-explotación de los recursos salvajes. Planteando, en un plano general desde la Antigüedad al final del período medieval, una perspectiva cuantitativa que avala esta postura, Guerreau, Alain. «Les structures de base de la chasse médiévale». En Paravicini Bagliani, Agostino y Van den Abeele, Baudouin (eds.). La chasse au Moyen Âge. Société, traités, symboles. Florencia: Sismel, 2000, p. 27. Rechaza, por el contrario, un consumo marginal de los productos cinegéticos, Montanari, L'alimentazione, pp. 256, 270.

60 Sin embargo, no siempre la muestra de conejo debe ser tomada en consideración para el análisis, al tratarse de un animal que frecuentemente contamina los contextos arqueológicos con sus madrigueras. VigilEscalera, Alfonso et al. "Productive Strategies and Consumption Patterns in the Early Medieval Village of Gózquez (Madrid, Spain)». Quaternary International, 2014, vol. 346, p. 12.

61 Grau-Sologestoa y García-García, «Zooarqueología», p. 353; Grau-Sologestoa, «Socioeconomic Status», p. 192. En este punto deberíamos destacar el yacimiento de El Castillón, donde se han encontrado evidencias excepcionalmente destacables de caza mayor, tales como astas de ciervo y garras de oso. Sastre Blanco, José Carlos et al. «El yacimiento de El Castillón en época visigoda (siglo vI): aspectos arquitectónicos y cultura material». En Álvarez Rodríguez, Alicia, Tejedor Rodríguez, Cristina y García Vázquez, Iván (eds.). Arqueología en el valle del Duero: Del Paleolítico a la Edad Media, 5. Valladolid: Glyphos, 2017, p. 396. La falta de estudios específicos nos impide saber aún si estaban asociados a contextos campesinos o de privilegio.

62 Grau Sologestoa, Idoia. "Ganadería en la Alta Edad Media. Estudio comparativo de los yacimientos alaveses de Zornoztegi, Zaballa y Salvatierra-Agurain». Munibe, 2009, vol. 60, p. 277. Dentro de estos marcadores arqueológicos de la presencia de grupos privilegiados se deben considerar también los restos zooarqueológicos. Grau-Sologestoa, «Socioeconomic Status», p. 194. A fin de cuentas, y haciéndonos eco de las palabras de García-Collado, «Food Consumption Patterns», p. 59: «Access to food is conditioned by economic position and this is commonly linked to social status». Sobre otros marcadores de poder en el registro 
consumo de carne de caza ${ }^{63}$, lo que apunta a un relativo desinterés por esta práctica, al menos como vía de obtención de alimentos ${ }^{64}$. Respecto a esta ausencia de evidencias arqueológicas, es posible que el producto de la caza no fuese en sí mismo un signo de distinción para los grupos privilegiados, ni siquiera fuese la captura de carne de animales salvajes el objetivo prioritario para estos ${ }^{65}$, sino la práctica cinegética en sí misma, al ser en ella donde se mostraban los valores militares y viriles que se querían reclamar ${ }^{66}$. Aun así, las evidencias apuntan a que la caza habría actuado únicamente de forma esporádica como actividad de recreo para las élites, de ahí que en el caso visigodo no adquiriese nunca una significación simbólica visible.

Es posible que culturalmente, en un marco mental cristiano, no estuviese bien percibida la ingesta de productos cárnicos entre los ámbitos aristocráticos; una idea que choca con la creencia común de ver en estos períodos de influjo bárbaro un momento de revalorización social del consumo de carne ${ }^{67}$. De esta manera, Sidonio Apolinar, en el retrato que hace de Veccio, destaca la abstinencia que hacía el inlustris uiri de carne de caza, como si de un monje se tratase, lo que sirve al autor para exaltar aún más la figura y las virtudes nobles del retratado ${ }^{68}$. Una abstinencia similar se habría exigido en los entornos eclesiásticos, ya no solo en los monásticos ${ }^{69}$, sino también en los episcopales. Por

arqueológico del momento, Quirós Castillo, Juan Antonio. «Archaeology of Power and Hierarchies in Early Medieval Villages in Northern Spain». En Klápště, Jan (ed.). Hierarchies in rural settlements. Turnhout: Brepols, 2013, pp. 199-112.

63 Yvinec, Jean-Hervé. "Le part du gibier dans l'alimentation du haut Moyen Âge». En Desse, Jean y Audoin-Rouzeau, Frederique (eds.). Exploitation des animaux sauvages à travers le temps. Juan-les-Pins: Éditions APDCA, 1983, p. 502; Guerreau, «La caza», p. 137. Tal y como señala el mismo autor en otro trabajo, «la venaison comme alimentation aristocratique est un exemple presque idéal de pure construction idéologique». Guerreau, «Les structures», p. 27. Algunos, sin embargo, ven en la caza la principal fuente de alimentación de las élites. Montanari, L'alimentazione, p. 270. Con independencia del grupo social, habría predominado el consumo de carne vacuna, ovicaprina y porcina. Audoin-Rouzeau, «L'alimentation carnée», pp. 77-100.

64 Este hecho puede ponerse en relación con la ausencia de libros caza, género literario más propio de momentos posteriores, cuando la práctica cinegética adquirió otro significado y valor. Véase Fradejas Rueda, José Manuel. «Iluminar la caza en la Edad Media: aproximación a la iconografía venatoria medieval iberorrománica». Revista de Poética Medieval, 2016, vol. 30, pp. 105-130.

65 Guerreau, «La caza», p. 137. Un punto de vista alternativo en: Le Jan, «Soustraire, négocier», p. 71.

${ }_{66}$ Guizard-Duchamp, «Les espaces», p. 124. Aplicado al contexto ibérico, Grau-Sologestoa, «Socioeconomic Status», p. 194.

${ }_{67}$ Así se manifiestan, por ejemplo, Riera i Melis, Antoni. «Las restricciones alimenticias como recurso expiatorio en algunas reglas monásticas de los siglos vi y viı». Aragón en la Edad Media, 1999, vol. 14-15, n. ${ }^{\circ}$ 2, pp. 1303-1304; Plouver, Liliane. "L'alimentation carnée au Haut Moyen Âge d'après le De observatione ciborum d'Anthime et les Excerpta de Vinidarius». Revue Belge de Philologie et d'Histoire, 2002, vol. 80, n.o 4, 2002, pp. 1357-1369; Velázquez, Isabel. «El vocabulario latino sobre la alimentación en la Antigüedad tardía». Antiquité Tardive, 2019, vol. 27, p. 26.

${ }_{68}$ Sid. Apoll., Ep. IV, 9, 3. Sobre la actitud de Sidonio en cuanto a la alimentación, véase Shanzer, Danuta. «Bishops, Letters, Fast, Food, and Feast in Later Roman Gaul». En Mathisen, Ralph W. y Shanzer, Danuta (eds.). Society and Culture in Late Antique Gaul. Revisiting the Sources. New York: Routledge, 2001, pp. 220-222.

69 La regla fructuosiana permite únicamente el consumo de carne a los monjes en circunstancias muy particulares, como por ejemplo a aquellos que cayesen enfermos o que tuviesen que salir de viaje. Boulc'h, Stéphane. "Le repas quotidien des moines occidentaux du haut Moyen Âge». Revue Belge de Philologie et 
ejemplo, llama la atención que, entre los distintos intercambios de regalos en forma de comida que se conocen entre obispos, la carne no forma nunca parte de estos ${ }^{70}$. Es cierto que, en ocasiones, la realidad habría ido al margen de los estereotipos culturales recogidos en las fuentes. De esta manera, sabemos que miembros de la alta jerarquía eclesiástica hispanovisigoda, como Leandro de Sevilla, pero también el propio papa Gregorio Magno, padecían de podagra o gota, una afección vinculada, entre otras posibles causas, al consumo frecuente de carne de caza ${ }^{71}$. También Ruricio de Limoges, en una comunicación con un noble galorromano, Constancio, habla de la recepción de aves como regalo, presumiblemente destinadas a su consumo ${ }^{72}$. Sin embargo, por nuestra parte preferimos interpretar estos casos más en clave de excepcionalidad, prefiriendo ver en la frugalidad la tendencia predominante en la dieta visigoda.

\section{LA CAZA EN LOS HORIZONTES CAMPESINOS}

La carencia documental se reproduce también cuando pretendemos aproximarnos a las dinámicas cinegéticas en los contextos campesinos, así como a su gestión. Aquí se imbrican varias problemáticas de compleja resolución. Por un lado, tendríamos aquella relativa a la naturaleza de las propiedades donde se ejercía la caza; por otro lado, el condicionamiento de esta primera cuestión en el uso de tales espacios, esto es, quién podía ejercer la caza en un determinado espacio en función de quién ostentaba la propiedad; $y$, por último, los límites en la explotación de los recursos cinegéticos, es decir, en función de los factores anteriores, hasta qué punto una persona podía ejercer la caza en tales espacios. Para responder a tales cuestiones dependemos en exclusiva del discurso legislativo, que nos ofrece las pocas pistas que nos permiten rastrear las dinámicas cinegéticas más comunes. A este problema de base se unen los generados por la propia historiografía, que ha incluido en el análisis de este tema algunas normas que, a nuestros ojos, en ningún momento se concibieron para regular el ejercicio de la caza. Este el caso de la ley VIII, 4, 22 del Liber Iudiciorum, que se ha aducido como evidencia a este respecto, en concreto en lo referido a los derechos de los propietarios. La ley en cuestión carga las culpas sobre todo aquel individuo que sufre daños al invadir con intenciones maliciosas un campo

d'Histoire, 1997, vol. 75, n. ${ }^{\circ}$ 2, p. 299. No obstante, se advierten diferencias en función de las comunidades monásticas, puesto que no contamos con limitaciones similares para aquellos monasterios regidos por la Regla Común. Díaz, Pablo C. Formas económicas y sociales del monacato visigodo. Salamanca: Ediciones Universidad de Salamanca, 1987, pp. 101-102. Véase también Riera i Melis, «Las restricciones», pp. 1303-1316; Madrid Medrano, Sonia. "La alimentación monástica en la Antigüedad tardía». Antiquité Tardive, 2019, vol. 27, pp. 153-154.

70 Shanzer, «Bishops, Letters», p. 235.

71 Greg. Magn., Reg. Ep. IX, 128. Ed. Dag Norberg y Vincenzo Recchia. Registrum Epistularum (VIIIX) - Lettere (VIII-X). Roma: Città Nuova Editrice, 1998, p. 490. Véase Menéndez Bueyes, Luis R. «Medicina, enfermedad y muerte en la Italia Tardoantigua: Un acercamiento a través de los Dialogi de Gregorio Magno». Helmántica, 2013, vol. 64, n. ${ }^{\circ} 191$, pp. 119-120. Mi agradecimiento al autor por su desinteresado asesoramiento.

72 Rur. Lemov., Ep. II, 43. Ed. Roland Demeulenaere. Foebadius, Victricius, Leporius, Vincentius Lerinensis, Evagrius, Ruricius. CC, Series Latina, LXIV. Turnhout: Brepols, 1985, pp. 380-381. 
o una vińa protegidos por estacas ${ }^{73}$. Eduardo Pérez Pujol adujo que tales medidas de protección tenían una finalidad cinegética ${ }^{74}$. Sin embargo, por nuestra parte las consideramos únicamente una evidencia de los medios empleados por los propietarios o arrendatarios de una tierra para proteger los cultivos de posibles incursiones de animales salvajes o de ganado ajeno. Caso distinto sería el de la ley VIII, 4, 23. Esta norma contempla dos supuestos, por un lado, aquellas prácticas destinadas a proteger los campos de cultivo de la incursión de animales salvajes, en este caso a través de fosos, y, por otro lado, a aquellas otras, ahora sí, propias de la actividad cinegética. En concreto, la ley establece, por un lado, la compensación que el cazador debía dar si alguna cabeza de ganado ajena moría o era herida a causa de trampas que, según prescribe la ley, en principio debían situarse en lugares apartados o desiertos no transitados (in locis secretis vel desertis). Por otro lado, la norma establece la obligatoriedad de notificar a los vecinos la presencia de tales trampas con el fin de evitar daños y las consecuencias jurídicas en caso de que cayese en ellas un visitante a quien no se podía haber notificado el aviso de su presencia ${ }^{75}$. Por lo tanto, contamos con una única ley que regula directamente la práctica cinegética, y ni siquiera de forma exclusiva.

Dada esta carencia de regulaciones de la actividad cinegética, debemos recurrir a otras normas que, aun sin tratar directamente este asunto, lo condicionan. También los propios silencios legislativos pueden ser útiles a la hora de conocer las pervivencias con respecto a la etapa precedente y las particularidades propias del sistema visigodo frente a otros contemporáneos. En la etapa precedente la caza no fue nunca concebida como un privilegio. Era una actividad abierta a todos, res nullius, sin restricción jurídica en su ejercicio con independencia de los espacios y de la condición social de cada persona. Se consideraba, de hecho, un derecho natural a todo hombre, y no un derecho concedido por el legislador, fenómeno más propio de momentos medievales ${ }^{76}$. La propia falta de leyes que modificaran las costumbres precedentes apunta así a una continuidad de estos mismos principios de libertad que rigieron la práctica cinegética en época tardorromana ${ }^{77}$. En

$73 L V$, VIII, 4, 22. Ed. Karl Zeumer. Leges Visigothorum. MGH, Legum Sectio I, Legum Nationum Germanicarum, T. I, Hannover-Leipzig, 1902, p. 340.

74 Así lo hace, por ejemplo, Pérez Pujol, Historia, pp. 340-341.

$75 L V$, VIII, 4, 23.

76 Véase García Garrido, «Derecho de caza», pp. 271-272; Cigolini, Il diritto, pp. 4-5; de los Mozos, "Precedentes históricos», p. 286-287; Pérez Vicente, Isabel. «Legislación cinegética en España: evolución y actualidad». Agricultura y sociedad, 1991, vol. 58, p. 174-175; Laguna de Paz, José Carlos. Libertad y propiedad en el derecho de caza. Madrid: Marcial Pons, 1997; Devroey, Économie rurale, p. 91. Defiende, por el contrario, restricciones a su práctica, Pérez Pujol, Historia, p. 341. El trabajo de referencia sobre la práctica cinegética en Roma es Aymard, Jacques. Essai sur les chasses romaines: des origines à la fin du siècle des Antonins. París: E. de Boccard, 1951.

77 Abogando por esta libertad de caza, Torres López, Lecciones, pp. 144-145; Fradejas Rueda, José Manuel. «El noble exerçiçio de caça y monte». Estudios Mirandeses, 2007, vol. 27, pp. 97-112. Un punto de vista alternativo en Pérez Pujol, Historia, pp. 341-342; Vázquez Cañizares, Evolución, p. 41. Esta idea choca frontalmente con aquellas posturas que, desde la historia jurídica, abogan por una ruptura entre el derecho romano y el germánico o, en su defecto, por una fuerte incidencia de las prácticas jurídicas germánicas en la economía visigoda. Esta es la perspectiva que siguen, entre otros: Gibert, «Introducción», pp. 33-34; Morales Muñiz y Morales Muñiz, «¡De quién?», p. 389; Vázquez Cañizares, Evolución, pp. 39-40. Criticando esta tendencia, Beneyto, Juan. Estudios sobre la historia del régimen agrario. Barcelona: Bosch, 1941, p. 82. 
otras palabras, el ejercicio de la caza no estaba vinculada a la propiedad, lo que contrasta con la realidad franca, donde se emitió una legislación específica que preservaba los derechos de propiedad sobre los animales salvajes para evitar su robo, lo que en la práctica suponía una limitación al libre ejercicio de la caza ${ }^{78}$. Por otro lado, y en relación con esto último, la legislación visigoda no contempla los animales salvajes como propiedades ${ }^{79}$, es decir, "los animales salvajes no eran parte del fundo ni accesorio del mismo» ${ }^{80}$. Se perpetúa así también la noción romana que se tenía de los animales salvajes, apropiables únicamente por la vía de la ocupatio ${ }^{81}$ : «los animales salvajes cazados son propiedad del cazador por el derecho de gentes, pues lo que antes no es de nadie, se concede por razón natural al que lo ocupa, sin importar si se caza en fundo propio o ajeno» ${ }^{82}$.

En lo que se refiere a las limitaciones en el ejercicio de la caza, la legislación visigoda únicamente contempla como restricción de la actividad venatoria el no colocar trampas en los caminos o en los lugares de tránsito y pasto del ganado, de ahí la preferencia hacia espacios más marginales y poco aptos para el pastoreo ${ }^{83}$. Sin embargo, esta medida no estaba destinada a limitar el ejercicio de la caza, sino a preservar la integridad física de los transeúntes y el ganado. De hecho, ninguna norma prohíbe la entrada o el tránsito de personas en propiedades ajenas, ya fueran cultivos o explotaciones ganaderas, y por tanto tampoco el ejercicio de la caza. En esto último vemos precisamente una diferencia respecto a la legislación romana, que garantizaba al propietario el ius prohibendi, es decir, la capacidad de autorizar o denegar a una persona el acceso a sus predios ${ }^{84}$. Cuando se regula la entrada de alguien en un predio, como en la ya citada norma VIII, 4, 22, se especifica claramente que el castigo o, como en este caso, la ausencia de compensaciones por dańos y perjuicios venían si la persona en cuestión invadía la heredad con intenciones malicio$\operatorname{sas}^{85}$. Por tanto, el seńor no podía prohibir la entrada en sus predios para el ejercicio de la caza. La única restricción vigente era el respeto debido a la propiedad y, por extensión, la seguridad de los cultivos y del ganado ajenos. El cazador se veía así prácticamente libre de limitaciones legales para llevar a cabo su actividad en propiedades privadas. Es posible

78 Le Jan, «Espaces sauvages», p. 42.

79 Únicamente se plantea para los animales domésticos. $L V$, VIII, 5, 6.

80 Mesa Gutiérrez, M. Juncal. Marco penal y administrativo de la caza y responsabilidad civil en derecho español. Madrid: Universidad Complutense de Madrid, 2017 [Tesis doctoral inédita], p. 31.

81 García Garrido, «Derecho de caza», pp. 272-281; Gibert, «Introducción», p. 33.

82 Mesa Gutiérrez, Marco penal, pp. 30-31.

$83 L V$, VIII, 4, 23. Esta ley bebe directamente del derecho romano, al recogerse en el Digesto una sentencia del jurista romano Paulo (Comm. Sab., 10) referida a la caza que guarda un enorme parecido con la norma visigoda. Digesta IX, 2, 28. Ed. Theodor Mommsen. Digesta. Corpus Iuris Civilis, Vol. I. Berlin: Apud Weidmannos, 1889, p. 128. Haciéndose eco de esta norma, De los Mozos, «Precedentes históricos», p. 288. Sobre la tipología de trampas empleadas en el período medieval, Bord y Mugg, La chasse, pp. 266-271. No descartamos que las trampas, en forma de fosos y redes, hubiesen sido empleadas como instrumento complementario en los ejercicios cinegéticos de la aristocracia. A ello apunta el testimonio de Sidonio Apolinar (Ep. VIII, 6, 12).

$84 \mathrm{Al}$ respecto de esta cuestión, véase Lombardi, Gabrio. «Libertà di caccia e proprietà privata in diritto romano", Bullettino dell'Istituto di Diritto Romano, 1948, vol. 12, n. ${ }^{\circ}$ 53-54, pp. 273-343. García Garrido, "Derecho de caza», pp. 269-336, esp. 316-318.

${ }_{85} L V$, VIII, 4, 22. 
incluso que en muchas ocasiones el dueño o el arrendatario de un cultivo o de un espacio inculto hubiesen aceptado de buen gusto el ejercicio de la caza en sus tierras, al acabar así con aquellos animales salvajes que podían provocar dańos sobre sus explotaciones ${ }^{86}$. No queremos negar con esto la aparición de problemas y dańos como consecuencia de ello $^{87}$. Sin embargo, el hecho de que estos no hayan dejado huella legal alguna nos induce a pensar que tales conflictos se dieron de forma bastante excepcional, al menos en comparación con aquellos referidos a la actividad ganadera, mucho más presentes en la legislación; y cuando se dieron, se habrían solucionado preeminentemente por acuerdos verbales o recurriendo al derecho consuetudinario local vigente, igualmente efectivo a la hora de resolver conflictos ${ }^{88}$. En otras palabras, en ningún momento se habrían tratado de problemas habituales que hubiesen requerido una normativización escrita de sus posibles vías de resolución.

En resumen, podríamos hablar de un uso comunal de la propiedad privada en lo que a la caza se refiere ${ }^{89}$. Insistimos aquí en el carácter particular de tales propiedades, puesto que uso comunal no implica necesariamente propiedad común, a pesar de que algunos autores hayan asumido este principio para buena parte de las leyes referidas a la ganadería, y en concreto en lo que se refiere a los espacios no cercados ${ }^{90}$. Las normas en las que estos se apoyan únicamente abogan por un uso comunal de los espacios incultos, uacantes, pero las evidencias no permiten certificar una propiedad colectiva de estos ${ }^{91}$.

86 Es en este tipo de espacios abiertos y cultivados donde la cetrería mostraría su mayor potencial. Guerreau, «La caza», p. 138; Salisbury, The Beast, p. 53.

87 Valga recordar los daños generados por las tropas visigodas en el territorium de Arlés en el transcurso de partidas de caza contra los jabalíes que rondaban las tierras de los campesinos. Vita Caesarii I, 48.

${ }_{88}$ Debemos considerar esta coexistencia de mecanismos formales e informales de resolución de conflictos y de gestión de los espacios de producción económica. North, Douglas N. Understanding the Process of Economic Change. Princeton-Oxford: Princeton University Press, 2005, p. 48. Tales usos jurídicos basados en la costumbre guardaban ecos del derecho romano tardío. Sobre la permanencia del derecho consuetudinario en la sociedad hispanovisigoda: Pérez-Prendes, José Manuel. Curso de Historia del Derecho Español. Madrid: Servicio Publicaciones Facultad de Derecho, UCM, vol. 1, 1989, p. 427-428; Petit, Carlos. Ivstitia gothica. Historia social y Teología del proceso en la Lex Visigothorum. Huelva: Publicaciones Universidad de Huelva, 2001, pp. 33-38, aunque ambos autores discrepan en torno a la raíz romana o germánica de dichas costumbres. Muchas de estas prácticas consuetudinarias propias de cada comunidad habrían llegado a perdurar hasta tiempos relativamente recientes. Costa, Joaquín. Colectivismo agrario en España. Madrid: Imprenta de San Francisco de Sales, 1898.

89 Haciéndonos eco de las palabras de Devroey, Économie, p. 83: «ce qui compte dans la société médiévale, ce sont moins les droits de propriété que les droits d'usage». Rechazamos, por tanto, la radicalidad de Beneyto, Estudios, pp. 63-64, quien en su análisis de las dinámicas ganaderas visigodas niega aprovechamientos comunales de los espacios privados. Es este mismo autor quien ofrece una definición sobre aprovechamientos comunales: «Derecho correspondiente a un conjunto o comunidad de 'consortes'. Típicamente se refiere a la utilización de prados, bosques y aguas estimada accesorio de cada una de las fincas del distrito y gozada en términos proporcionales por los 'herederos' propietarios o poseedores del consorcio». Ibidem, p. 46.

90 Entre otros, Pérez Pujol, Historia, pp. 347-348. Ello no quiere negar la existencia de propiedades compartidas o, incluso, comunales. Torres López, Lecciones, p. 138; García Gallo, Alfonso. «Notas sobre el reparto de tierras entre visigodos y romanos». Hispania, 1941, vol. 4, p. 51. Un buen estudio sobre estos espacios de propiedad compartida en Beneyto, Estudios.

91 Este es el caso de $L V$, VIII, 3, 9. Considerando tales espacios como propiedad de un particular, King, Derecho, p. 226. 
Dentro de estos espacios privados de uso comunal se integrarían también los bosques, escenarios preferentes para el ejercicio de la caza, y donde esta actividad coincidiría espacialmente con la explotación ganadera ${ }^{92}$. Observamos así cómo en un mismo espacio, fuese este agrario - tal y como hemos señalado anteriormente- o ganadero, podían converger distintas actividades económicas que, por su naturaleza compatible, no tenían que generar necesariamente problemas entre los usuarios.

Por otro lado, la ausencia de una legislación específica y profusa referida a esta actividad que apunte a la aparición habitual de conflictos, a una competencia entre cazadores por la explotación de un mismo espacio cinegético o a una necesidad de control ecológico nos permite inferir un cierto desinterés general por parte de la sociedad visigoda hacia la caza como recurso económico o como fuente de alimento ${ }^{93}$. De esta manera, en los contextos campesinos habría predominado la ganadería como vía de consumo de carne ${ }^{94}$, siendo los productos derivados de la caza consumidos de forma muy esporádica — tanto por desinterés como por falta de medios - a partir de los animales capturados en las propias explotaciones agrícolas y ganaderas ${ }^{95}$.

Esta incidencia menor de la caza no implica necesariamente una ausencia de especialización en su desarrollo, tampoco en los contextos campesinos ${ }^{96}$. Las fuentes nos revelan incluso la existencia del oficio de cazador en la sociedad visigoda, que dedicaría el producto de la caza, fundamentalmente aves, a su venta ${ }^{97}$. Esta es la idea que nos transmite

92 Las Formulae visigodas recogen la prueba de que los bosques también entraban dentro del régimen de propiedad privada, y como tales se podían donar o transmitir por distintas vías. Form. Wisigoth. VIII, 1017; XX, 52-54; XXI, 9-15. Ed. J. Gil, Miscellanea Wisigothica. Sevilla: Publicaciones Universidad de Sevilla, 1972, pp. 80-81, 92, 94; Tomás-Faci, Guillermo y Martín-Iglesias, José Carlos. "Cuatro documentos inéditos del monasterio visigodo de San Martín de Asán (522-586)». Mittellateinisches Jahrbuch, 2017, vol. 52, n. 2, p. 280. Poniendo también de manifiesto esta naturaleza privada de los bosques, $L V$, VIII, 5 , 1, 3-4. Ponen de relieve la privatización de estos espacios, Torres López, Lecciones, pp. 137-138; García Gallo, «Notas», pp. 46-47. En un plano general, Verdon, "Recherches», pp. 808-809. Cf. Pérez Pujol, Historia, p. 350; Gibert, «Introducción», pp. 33-34; Pérez-Prendes, José Manuel. Breviario de derecho germánico. Madrid: Servicio de Publicaciones, Universidad Complutense, 1993, pp. 34-35.

93 En una línea similar se manifestó en su día Pérez Pujol, Historia, p. 339.

94 King, Derecho, p. 243. Aun así, la incidencia del consumo de carne en la dieta campesina era muy limitado, o así lo revelan los estudios zooarqueológicos y los análisis isotópicos realizados recientemente en Gózquez, un contexto rural eminentemente campesino y donde las evidencias de consumo de productos de caza son meramente testimoniales. Vigil-Escalera et alii, «Productive Strategies», p. 12; García-Collado, «Food Consumption», pp. 71-73. Plantea, por el contrario, una importante incidencia de la caza en la alimentación campesina, Montanari, L'alimentazione, p. 270.

95 Ello no supone negar su papel como suplemento ocasional en la dieta cárnica de la sociedad en su conjunto. Grau-Sologestoa, «Socioeconomic Status», p. 194. Véase también Yvinec, Jean-Hervé. "L'élevage et la chasse. Étude de la faune sauvage et domestique. L'alimentation d'origine animale». En Un village au temps de Charlemagne. Moines et paysans de l'abbaye de Saint-Denis du vit siècle à l'An Mil. París: Éditions de la Réunion des Musées Nationaux, 1988, p. 227; Menéndez Bueyes, Luis R. "Condiciones de vida y enfermedad en la Tardoantigüedad. Una aproximación desde la parte occidental del antiguo Imperio romano». En Quirós Castillo, Juan Antonio (dir.). Demografía, paleopatologías y desigualdad social en el noroeste peninsular en época medieval. Bilbao: Universidad del País Vasco, Servicio Editorial, 2016, pp. 223-243, esp. 235-236.

96 Sobre esta cuestión, Pérez Pujol, Historia, p. 340.

${ }_{97}$ Es posible que las élites eclesiásticas, como los obispos anteriormente mencionados, adquiriesen la carne de caza a partir de su compra a estos cazadores. Véase supra. Esta especialización también se habría 
la Vita Fructuosi, cuando describe el encuentro de su protagonista con un cazador, que confundió al santo hombre con un animal salvaje. A este cazador se le describe portando un arco y preparando trampas ${ }^{98}$. Este último dato, unido a la norma anteriormente mencionada que regula la colocación de trampas, nos lleva a pensar en una primacía de la caza pasiva, es decir, aquella llevada a cabo por medio de trampas, contrastando así con la caza aristocrática, donde se valoraba más el valor y el riesgo. Por esta misma razón, la caza campesina habría tenido un carácter menor, centrada en animales inofensivos y fáciles de cazar, frente a la aristocrática, donde se valoraba más la caza mayor. Por otro lado, otra idea que nos transmite este episodio hagiográfico es que en ambientes campesinos la caza debió de llevarse a cabo principalmente de forma individual, al menos cuando esta se desarrollaba con un fin eminentemente económico y alimentario. Aun así, debemos suponer que algunas ocasiones muy puntuales se habría ejercido de forma colectiva, en concreto la caza defensiva dirigida contra animales salvajes peligrosos y otras alimañas, en especial contra lobos ${ }^{99}$.

\section{Conclusiones}

A modo de conclusión, frente a las dinámicas vigentes en otros escenarios geográficos del Occidente post-imperial, donde la caza adquirió una mayor relevancia social frente a la etapa romana que le precedió, en la sociedad visigoda la práctica cinegética desempeñó un rol social, económico y cultural menor, tanto en los escenarios aristocráticos como en los campesinos. Ello no supone negarle relevancia, especialmente en los escenarios aristocráticos, donde la caza desempeńó un papel importante como actividad de recreo y de distinción, pero es cierto que esta importancia fue relativa, al menos si la comparamos con las tendencias vigentes en los reinos vecinos. Como consecuencia de ello, mientras en el resto del Occidente post-imperial se empiezan a introducir dinámicas propias del período feudal, como era la limitación de uso de los espacios cinegéticos, en el reino visigodo apreciamos que se da continuidad a las costumbres romanas que hacían de la caza una actividad libre, abierta a todos, con independencia de los espacios y de la condición social y jurídica del individuo. No pretendemos con ello negar diferencias en función de los grupos sociales, ya no solo en su significado, sino también en su propia práctica. De esta manera, mientras la aristocracia habría optado por una caza colectiva y habría optado por una implicación mucho más activa en los episodios venatorios como consecuencia de la importancia social que tenía la caza como mecanismo de distinción; en los contextos campesinos la caza habría desempeñado un papel eminentemente económico y su práctica se habría llevado a cabo por mecanismos mucho menos arriesgados. Por

producido en el reino franco, donde conocemos cazadores responsables de proveer de productos de caza a la aristocracia. Greg. Tur., Lib. Vit. Patr. XII, 2. Ed. Bruno Krusch. Gregorii episcopi Turonensis miracula et opera minora. MGH, SRM Tom. I P. II. Hannover: Impensis Bibliopolii Hahniani, 1885, pp. 262-263.

98 Vit. Fruct. 5. Ed. Manuel C. Díaz y Díaz. La Vida de San Fructuoso de Braga. Estudio y edición crítica. Braga: [s.n.], 1974, p. 86. Es posible que la Vita Caesarii se estuviera refiriendo a estas figuras más especializadas al hablar de los cazadores que rondaban el entorno de Arlés en busca de jabalíes. Vita Caesarii I, 48.

99 Verdon, «Recherches», p. 826; Salisbury, The Beast, p. 44. 
otro lado, al hilo de la continuidad con las tendencias previas y en lo que a los horizontes campesinos se refiere, se advierte incluso la eliminación de algunas de las restricciones que habían estado vigentes en la etapa anterior y que habían limitado indirectamente la práctica cinegética, como era el ius prohibendi romano. Podemos hablar así de un avance de los derechos de aprovechamiento común de los espacios privados, tuvieran estos una naturaleza agraria o ganadera. La aprehensión de las dinámicas cinegéticas se torna así de enorme utilidad para ahondar en nuestro conocimiento sobre los distintos regímenes de propiedad vigentes en la sociedad visigoda y, dentro de estos, la convergencia de distintos usos económicos y jurídicos en un mismo espacio.

\section{ReFERENCIAS BIBLIOGRÁFICAS}

\section{FUENTES PRIMARIAS}

Agath. Hist. = Agathias, Historiae. Ed. Rudolf Keydell. Agathiae Myrinaei Historiarum libri quinque. Berlin: De Gruyter, 1967.

Concilia Galliae. A 314-A. 506. Ed. Charles Munier. Turnhout: Brepols, 1963.

Digesta. Ed. Theodor Mommsen. Digesta. Corpus Iuris Civilis, Vol. I. Berlin: Apud Weidmannos, 1889.

Diplom. Merov. = Diplomata regum Francorum e stirpe Merovingica . Ed. Theo Kölzer. Die Urkunden der Merowinger. MGH, Diplomata regum Francorum e stirpe Merovingica. Hannover: Impensis Bibliopolii Hahniani, 2001, vol. 1.

Edictus Rothari. Ed. Georg H. Pertzt. Leges Langobardorum. MGH, Legum, T. IV, Hannover: Impensis Bibliopoli Hahniani, 1868.

Epistula ad Wambanem principem. Ed. Wilhelm Levison. Sancti Iuliani Toletanae sedis episcopi opera, Pars I. CC, Series Latina, CXV. Turnhout: Brepols, 1976.

Form. Wisigoth. = Formulae Wisigothicae. Ed. Juan Gil. Miscellanea Wisigothica. Sevilla: Publicaciones Universidad de Sevilla, 1972.

Greg. Magn., Reg. Ep. = Gregorius Magnus, Registrum Epistularum. Ed. Dag Norberg y Vincenzo Recchia. Registrum Epistularum (VIII-X) - Lettere (VIII-X). Roma: Città Nuova Editrice, 1998.

Greg. Tur., DLH. = Gregorius Turonensis, Decem Libri Historiae. Ed. Bruno Krusch y Wilhelm Levison. Gregorii episcopi Turonensis Historiarum Libri X. MGH, SRM Tom. I P. I. Hannover: Impensis Bibliopolii Hahniani, 1951.

Greg. Tur., Lib. in Glor. Confess. = Gregorius Turonensis, Liber in Gloria Confessorum. Ed. Bruno Krusch. Gregorii episcopi Turonensis miracula et opera minora. MGH, SRM Tom. I P. II. Hannover: Impensis Bibliopolii Hahniani, 1885.

Greg. Tur., Lib. Vit. Patr. = Gregorius Turonensis, Liber Vitae Patrum. Ed. Bruno Krusch. Gregorii episcopi Turonensis miracula et opera minora. MGH, SRM Tom. I P. II. Hannover: Impensis Bibliopolii Hahniani, 1885.

Isid. Hisp., Etym. = Isidorus Hispalensis, Etymologiae. Ed. José Oroz Reta y Manuel-A. Marcos Casquero. Etimologías. Madrid: BAC, 2009.

Iul. Tolet., Hist. Wamb.= Iulianus Toletanus, Historiae Wambae. Ed. Wilhelm Levison. Sancti Iuliani Toletanae sedis episcopi opera, Pars I. CC, Series Latina, CXV. Turnhout: Brepols, 1976.

Lex Ribuaria. Ed. Franz Beyerle y Rudolf Buchner. Lex Ribuaria. MGH, LL nat. Germ., T. III, P. II, Hannover: Impensis Bibliopolii Hahniani, 1954. 
$L R V=$ Lex Romana Visigothorum. Ed. Gustav Friedrich Haenel. Lex Romana Visigothorum. Leipzig: B. G. Teubner, 1849.

$L V=$ Leges Visigothorum Ed. Karl Zeumer. MGH, Legum Sectio I, Legum Nationum Germanicarum, T. I, Hannover-Leipzig, 1902.

Rur. Lemov., Ep. = Ruricius Lemovicensis, Epistulae. Ed. Roland Demeulenaere. Foebadius, Victricius, Leporius, Vincentius Lerinensis, Evagrius, Ruricius. CC, Series Latina, LXIV. Turnhout: Brepols, 1985.

Sid. Apoll., Carm. = Sidonius Apollinaris, Carminae. Ed. André Loyen. Sidoine Apollinaire, Tome I, Poèmes. París: Les Belles Lettres, 1960.

Sid. Apoll., Ep. = Sidonius Apollinaris, Epistulae. Ed. André Loyé. Sidoine Apollinaire, Tome II, Lettres (Livres I-V)-Tome III, Lettres (Livres VI-IX). París: Les Belles Lettres, 1970.

Vita Caesarii. Ed. Bruno Krusch. Passiones vitaeque sanctorum aeui Merouingici et antiquiorum aliquot. MGH, SRM, T. III. Hannover: Impensis Bibliopolii Hahniani, 1896.

Vit. Fruct. = Vita Fructuosi. Ed. Manuel C. Díaz y Díaz. La Vida de San Fructuoso de Braga. Estudio y edición crítica. Braga: [s.n.], 1974.

\section{BiBLIOGRAFÍA}

Audoin-Rouzeau, Frédérique. «L'alimentation carnée dans l'Occident Antique, médiéval et moderne. Identités culturelles, sociales et regionales à travers le temps». En Laurioux, Bruno (ed.). Histoire et identités alimentaires en Europe. París: Hachette, 2002, pp. 77-100.

Aymard, Jacques. Essai sur les chasses romaines: des origines à la fin du siècle des Antonins. París: E. de Boccard, 1951.

Aymard, Jacques. «Sidoine Apollinaire et la chasse». En Renard, Marcel y Schilling, Robert (eds.). Hommages à Jean Bayet. Bruxelles: Latomus, 1964, pp. 47-53.

Baker, Polydora. «Le rôle de la chasse comme moyen de subsistance durant le haut Moyen Âge dans le nord de l'Italie: une comparaison des sources zooarchéologiques et historiques». En Desse, Jean y Audoin-Rouzeau, Frederique (eds.). Exploitation des animaux sauvages à travers le temps. Juan-les-Pins: Éditions APDCA, 1983, pp. 505-516.

Barbier, Josiane. «Le système palatial franc: genèse et fonctionnement dans le nord-ouest du regnum». Bibliothèque de l'École des Chartes, 1990, vol. CXLVIII, n. o 2, pp. 245-299.

Barbier, Josiane. «Les lieux du pouvoir en Gaule franque». En Ehlers, Caspar (ed.). Places of Power - Orte der Herrschaft - Lieux du Pouvoir. Göttingen: Vandenhoeck \& Ruprecht, 2007, pp. 227-246.

Beneyto, Juan. Estudios sobre la historia del régimen agrario. Barcelona: Bosch, 1941.

Betzig, Laura. «Hunting Kings». Cross-Cultural Research, 2008, vol. 42, n. ${ }^{\circ} 3$, pp. 270-289.

Bord, Lucien-Jean y Mugg, Jean-Pierre. La chasse au Moyen Age. Occident latin, VI'-XV' siècle. Chartres: Éditions du Gerfaut, 2008.

Boulc'h, Stéphane. «Le repas quotidien des moines occidentaux du haut Moyen Âge». Revue Belge de Philologie et d'Histoire, 1997, vol. 75, n. ${ }^{\circ} 2$, pp. 287-328.

Cardot, Fabienne. L'espace et le pouvoir. Étude sur l'Austrasie mérovingienne. París: Publications de la Sorbonne, 1987.

Cigolini, Francesco. Il diritto di caccia nella legislazione statale e regionale. Milano: A. Giuffrè, 1959.

Costa, Joaquín. Colectivismo agrario en España. Madrid: Imprenta de San Francisco de Sales, 1898. De los Mozos, José Luis. «Precedentes históricos y aspectos civiles del derecho de caza». Revista de Derecho Privado, 1972, vol. LVI, n.o 4, pp. 285-304. 
Deswarte, Thomas. «Une satire politique. La lettre de Paul à Wamba (672)». En Deswarte, Thomas, Herbers, Klaus y Sirantoine, Hélene (eds.). Epistola 1. Écriture et genre épistolaires $I V^{\bullet}-X I^{e}$ siècle. Madrid: Casa de Velázquez, 2018, pp. 129-137.

Devroey, Jean-Pierre. Économie rurale et société dans l'Europe franque (VI'-IXe siècles). Tome 1. Fondements matériels échanges et lien social. París: Belin, 2003.

Devroey, Jean-Pierre y Schroeder, Nicolas. «Beyond Royal Estates and Monasteries: Landownership in the Early Medieval Ardennes». Early Medieval Europe, 2012, vol. 20, n. ${ }^{\circ}$ 1, pp. 39-69.

Díaz, Pablo C. Formas económicas y sociales del monacato visigodo. Salamanca: Ediciones Universidad de Salamanca, 1987.

Fradejas Rueda, José Manuel. «El noble exerçiçio de caça y monte». Estudios Mirandeses, 2007, vol. 27, pp. 97-112.

Fradejas Rueda, José Manuel. «Iluminar la caza en la Edad Media: aproximación a la iconografía venatoria medieval iberorrománica». Revista de Poética Medieval, 2016, vol. 30, pp. 105-130.

García-Collado, Maite Iris. «Food Consumption Patterns and Social Inequality in an Early Medieval Rural Community in the Centre of the Iberian Peninsula». Quirós Castillo, Juan Antonio (ed.). Social Complexity in Early Medieval Rural Communities: The North-Western Iberia Archaeological Record. Oxford: Archaeopress, 2016, pp. 59-78.

García Gallo, Alfonso. «Notas sobre el reparto de tierras entre visigodos y romanos». Hispania, 1941, vol. 4, pp. 40-63.

García Garrido, Manuel J. «Derecho de caza y 'ius prohibendi’ en Roma». Anuario de Historia del Derechos Español, 1956, vol. XXVI, pp. 269-336.

Gibert, Rafael. «Introducción». En La acción administrativa en materia de montes y caza. Alcalá de Henares: Escuela Nacional de Administración Pública, 1970, pp. 9-57.

Giese, Martina. «Kompetitive Aspekte höfischer Jagdaktivitäten im Frühmittelalter». En Becher, Matthias y Plassmann, Alheydis (eds.). Streit am Hof im frühen Mittelalter. Göttingen: Vandenhoeck \& Ruprecht, 2011, pp. 263-284.

Grand, Roger y Delatouche, Raymond. L'agriculture au Moyen Âge. De la fin de l'Empire romain au XVI siècle. París: De Boccard, 1950.

Grau Sologestoa, Idoia. "Ganadería en la Alta Edad Media. Estudio comparativo de los yacimientos alaveses de Zornoztegi, Zaballa y Salvatierra-Agurain». Munibe, 2009, vol. 60, pp. 253-280.

Grau-Sologestoa, Idoia. «Socioeconomic Status and Religious Identity in Medieval Iberia: The Zooarchaeological Evidence». Environmental Archaeology, 2017, vol. 22, n. ${ }^{\circ}$ 2, 2017, pp. 189-199.

Grau-Sologestoa, Idoia y García-García, Marcos. «Zooarqueología y Edad Media en la península ibérica». En Quirós Castillo, Juan Antonio (ed.). Treinta años de Arqueología Medieval en España. Oxford: Archaeopress, 2018, pp. 341-364.

Guerreau, Alain. «Les structures de base de la chasse médiévale». En Paravicini Bagliani, Agostino y Van den Abeele, Baudouin (eds.). La chasse au Moyen Âge. Société, traités, symboles. Florencia: Sismel, 2000, pp. 25-32.

Guerreau, Alain. «La caza». En Le Goff, Jacques y Schmitt, Jean-Claude (eds.). Diccionario razonado del Occidente medieval. Madrid: Akal, 2003, pp. 137-145.

Guizard-Duchamp, Fabrice. «Les espaces du sauvage dans le monde franque: réalités et représentations». En Construction de l'espace au Moyen Âge: pratiques et représentations. París: Publications de la Sorbonne, 2007, pp. 117-129.

Halsall, Guy. «Predatory Warfare - the Moral and the Physical». En Keller, Rodolphe y Sarti, Laury (eds.). Pillages, tributs, captifs. Prédation et sociétés de l'Antiquité tardive au haut Moyen Âge. París: Éditions de la Sorbonne, 2018, pp. 53-68. 
Higounet, Charles. «Les forêts de l'Europe occidentale du v ${ }^{\mathrm{e}}$ au xi $\mathrm{xi}^{\mathrm{e}}$ siècle». En Agricoltura e mondo rurale in occidente. Spoleto: CISAM, 1966, pp. 343-398.

Jarnut, Jörg. «Die frühmittelalterliche Jagd unter rechts- und sozialgeschichtlichen Aspekten». En L'uomo di fronte al mondo animale nell'alto Medioevo. Spoleto: CISAM, 1985, vol. II, pp. 765-808.

King, Paul D. Derecho y sociedad en el reino visigodo. Madrid: Alianza, 1981.

Laguna de Paz, José Carlos. Libertad y propiedad en el derecho de caza. Madrid: Marcial Pons, 1997.

Le Jan, Régine. «Espaces sauvages et chasses royales dans le nord de la France. VII ${ }^{\text {ème }}$-IX ${ }^{\text {ème }}$ siècles». En Le paysage rural: réalités et représentations. Villeneuve d'Ascq: Université de Lille III, 1980, pp. 35-57.

Le Jan, Régine. «Soustraire, négocier, doner le sauvage au haut Moyen Âge». En Sabaté, Flocel (ed.). Natura i desenvolupament: el medi ambient a l'Edat Mitjana. Lleida: Pagès, 2007, pp. 57-72.

Lindner, Kurt. Die Jagd im frühen Mittelalter. Berlin: De Gruyter, 1940.

Llorente, Laura et al. "Earliest archaeozoological evidence of falconry in the Iberian Peninsula». En BoneCommons, 2010, Item \#1324. URL: http://alexandriaarchive.org/bonecommons/ exhibits/show/icaz2010París/session5_2_\%26_6_3/item/1324

Lombardi, Gabrio. «Libertà di caccia e proprietà privata in diritto romano", Bullettino dell'1stituto di Diritto Romano, 1948, vol. 12, n. ${ }^{\circ}$ 53-54, pp. 273-343.

Lorenz, Sönke. «Der Königsforst («forestis») in den Quellen der Merowinger- und Karolingerzeit: Prolegomena zu einer Geschichte mittelalterlicher Nutzwälder». En Bauer, Dieter R., Hiestand, Rudolf, Kasten, Brigitte y Lorenz, Sönke (eds.). Mönchtum - Kirche - Herrschaft: 750-1000. Sigmaringen: Jan thorbecke Verlag, 1998, pp. 261-285.

Madrid Medrano, Sonia. «La alimentación monástica en la Antigüedad tardía». Antiquité Tardive, 2019, vol. 27, pp. 149-157.

Martín-Iglesias, José Carlos, Díaz, Pablo C. y Vallejo Girvés, Margarita. La Hispania tardoantigua y visigoda en las fuentes epistolares. Antología y comentario. Madrid: CSIC, 2020.

Menéndez Bueyes, Luis R. «Medicina, enfermedad y muerte en la Italia Tardoantigua: Un acercamiento a través de los Dialogi de Gregorio Magno». Helmántica, 2013, vol. 64, n.o 191, pp. 109-151.

Menéndez Bueyes, Luis R. "Condiciones de vida y enfermedad en la Tardoantigüedad. Una aproximación desde la parte occidental del antiguo Imperio romano». En Quirós Castillo, Juan Antonio (dir.). Demografía, paleopatologias y desigualdad social en el noroeste peninsular en época medieval. Bilbao: Universidad del País Vasco, Servicio Editorial, 2016, pp. 223-243.

Mesa Gutiérrez, M. ${ }^{a}$ Juncal. Marco penal y administrativo de la caza y responsabilidad civil en derecho español. Madrid: Universidad Complutense de Madrid, 2017 [Tesis doctoral inédita].

Montanari, Massimo. L'alimentazione contadina nell'alto Medioevo. Napoli: Liguori, 1979.

Montanari, Massimo. "Gli animali e l'alimentazione umana», en L'uomo di fronte al mondo al mondo animale nell'alto Medioevo. Spoleto: CISAM, 1984, pp. 619-672.

Montanari, Massimo. «La foresta come spazio economico e culturale». En Uomo e spazio nell'alto Medioevo. Spoleto: CISAM, 2003, pp. 301-340.

Morales Muñiz, Arturo y Morales Muñiz, Dolores Carmen. «¿De quién es este ciervo?: algunas consideraciones en torno a la fauna cinegética de la España medieval». En Clemente Ramos, Julián (coord.). El medio natural en la España medieval. Cáceres: Universidad de Extremadura, 2001, pp. 383-406.

Morsel, Joseph. «Construire l'espace sans la notion d'espace: Le cas du Salzforst (Franconie) au $\mathrm{XvI}^{\mathrm{e}}$ siècle». En Construction de l'espace au Moyen Âge: pratiques et représentations. París: Publications de la Sorbonne, 2006, pp. 295-316. 
North, Douglas N. Understanding the Process of Economic Change. Princeton-Oxford: Princeton University Press, 2005.

Pacaut, Marcel. «Esquisse de l'évolution du droit de chasse au haut Moyen Âge». En La chasse au Moyen Âge. París: Les Belles Lettres, 1980, pp. 59-68.

Pearson, Kathy. «Salic Law and Barbarian Diet». En Mathisen, Ralph W. (ed.). Law, Society, and Authority in Late Antiquity. New York-Oxford: Oxford University Press, 2001, pp. 272-285.

Pérez-Prendes, José Manuel. Curso de Historia del Derecho Español. Madrid: Servicio Publicaciones Facultad de Derecho, UCM, vol. 1, 1989.

Pérez-Prendes, José Manuel. Breviario de derecho germánico. Madrid: Servicio de Publicaciones, Universidad Complutense, 1993.

Pérez Pujol, Eduardo. Historia de las instituciones sociales de la España goda. Valencia: Establecimiento tipográfico F. Vives Mora, 1896, vol. IV.

Pérez Vicente, Isabel. «Legislación cinegética en España: evolución y actualidad». Agricultura y sociedad, 1991, vol. 58, pp. 173-185.

Petit, Carlos. Ivstitia gothica. Historia social y Teología del proceso en la Lex Visigothorum. Huelva: Publicaciones Universidad de Huelva, 2001.

Plouver, Liliane. «L'alimentation carnée au Haut Moyen Âge d'après le De observatione ciborum d'Anthime et les Excerpta de Vinidarius». Revue Belge de Philologie et d'Histoire, 2002, vol. 80, n.o 4, 2002, pp. 1357-1369.

Quirós Castillo, Juan Antonio. «Archaeology of Power and Hierarchies in Early Medieval Villages in Northern Spain». En Klápště, Jan (ed.). Hierarchies in rural settlements. Turnhout: Brepols, 2013, pp. 199-112.

Raga, Emmanuelle. «Réflexions sur le rapport ville/campagne dans l'Antiquité tardive au travers de quelques discours sur la chasse». Revue Belge de Philologie et d'Histoire, 2011, vol. LXXXIX, n. ${ }^{\circ} 2$, pp. 659-667.

Riera i Melis, Antoni. "Las restricciones alimenticias como recurso expiatorio en algunas reglas monásticas de los siglos vi y viı». Aragón en la Edad Media, 1999, vol. 14-15, n. ${ }^{\circ} 2$, pp. 1303-1316.

Rollason, David. «Forests, Parks, Palaces, and the Power of Place in Early Medieval Kingship». Early Medieval Europe, 2012, vol. 20, n. ${ }^{\circ} 4$, pp. 428-449.

Rösener, Werner. «Der König als Jäger. Antike Einflüsse auf di herrschaftliche Jagd im Mittelalter». En Martini, Wolfram (ed.). Die Jagd der Eliten in den Erinnerungskulturen von der Antike bis in die Frühe Neuzeit. Göttingen: Vandenhoeck \& Ruprecht, 2000, pp. 15-37.

Rösener, Werner (ed.). Jagd und höfische Kultur im Mittelalter. Göttingen: Vandenhoeck \& Ruprecht, 2000.

Salisbury, Joyce E. The Beast Within. Animals in the Middle Ages. New York: Routledge, 1994.

Sastre Blanco, José Carlos et al. «El yacimiento de El Castillón en época visigoda (siglo vi): aspectos arquitectónicos y cultura material». En Álvarez Rodríguez, Alicia, Tejedor Rodríguez, Cristina y García Vázquez, Iván (eds.). Arqueología en el valle del Duero: Del Paleolítico a la Edad Media, 5. Valladolid: Glyphos, 2017, pp. 383-398.

Shanzer, Danuta. «Bishops, Letters, Fast, Food, and Feast in Later Roman Gaul». En Mathisen, Ralph W. y Shanzer, Danuta (eds.). Society and Culture in Late Antique Gaul. Revisiting the Sources. New York: Routledge, 2001, pp. 217-236.

Tomás-Faci, Guillermo y Martín-Iglesias, José Carlos. «Cuatro documentos inéditos del monasterio visigodo de San Martín de Asán (522-586)». Mittellateinisches Jahrbuch, 2017, vol. 52, n. ${ }^{\circ}$ 2, pp. 261-286.

Torres López, Manuel. Lecciones de Historia del Derecho Español, II. Salamanca: Librería General 'La Facultad' de Germán García, 1935-1936. 
Valverde Castro, M. ${ }^{a}$ Rosario. Ideología, simbolismo y ejercicio del poder real en la monarquía visigoda: un proceso de cambio. Salamanca: Universidad de Salamanca, 2000.

Vázquez Cañizares, Julio César. Evolución histórico-legislativa de la caza furtiva. Móstoles: Crealite, 2014.

Velázquez, Isabel. «El vocabulario latino sobre la alimentación en la Antigüedad tardía». Antiquité Tardive, 2019, vol. 27, pp. 25-34.

Verdon, Jean. "Recherches sur la chasse en Occident durant le haut Moyen Âge». Revue Belge de Philologie et d'Histoire, 1978, vol. LVI, n. ${ }^{\circ} 4$, pp. 805-829.

Vigil-Escalera, Alfonso et al. "Productive Strategies and Consumption Patterns in the Early Medieval Village of Gózquez (Madrid, Spain)». Quaternary International, 2014, vol. 346, pp. 7-19.

Wickham, Chris. «European Forests in the Early Middle Ages: Landscape and Land Clearance». En L'ambiente vegetale nell'alto Medioevo. Spoleto: CISAM, 1990, pp. 479-548.

Wickham, Chris. Una historia nueva de la Alta Edad Media, 400-800. Barcelona: Crítica, 2009.

Wolfram, Herwig. History of the Goths. Berkeley: California University Press, 1988.

Yvinec, Jean-Hervé. «Le part du gibier dans l'alimentation du haut Moyen Âge». En Desse, Jean y Audoin-Rouzeau, Frederique (eds.). Exploitation des animaux sauvages à travers le temps. Juan-les-Pins: Éditions APDCA, 1983, pp. 491-504.

Yvinec, Jean-Hervé. «L'élevage et la chasse. Étude de la faune sauvage et domestique. L'alimentation d'origine animale». En Un village au temps de Charlemagne. Moines et paysans de l'abbaye de Saint-Denis du VII' siècle à l'An Mil. París: Éditions de la Réunion des Musées Nationaux, 1988, pp. 226-241. 